\title{
ESTIMATIVA DA ÁREA OCUPADA POR REFLORESTAMENTOS NO ESTADO DO RIO DE JANEIRO
}

\author{
Hugo Barbosa Amorim¹, Márcio Rocha Francelino², Samara Salamene³, Luiz Octavio Lima Pedreira ${ }^{4}$, \\ Luiz Ireno de Assumpção Filho ${ }^{4}$, Rodrigo Correa Capitano ${ }^{4}$, Tom Adnet Moura ${ }^{5}$
}

(recebido: 16 de abril de 2010; aceito: 29 de setembro de 2011)

\begin{abstract}
RESUMO: Este estudo fundamentou-se em levantamento e cadastro preliminar dos reflorestamentos existentes no Estado do Rio de Janeiro, por meio de técnicas de geoprocessamento e coleta de informações no campo. A área reflorestada encontrada foi de 18.426,96 ha, que corresponde a 0,42\% do território do Estado. Grande parte dos reflorestamentos consiste em plantios de eucalipto (98\%), seguido de pinus (0,8\%), e o restante encontra-se distribuído em outras 10 espécies. A Região do Médio Paraíba foi a que mais contribuiu para área reflorestada no Estado (46,6\%). O volume de madeira estimado para o eucalipto foi de quase dois milhões de metros cúbicos. Este estudo serviu para cristalizar a percepção corrente entre todos aqueles que militam no setor florestal fluminense, de que é incipiente a área plantada e o estoque de madeira oriunda de reflorestamentos existentes no Estado do Rio de Janeiro.

Palavras-chave: Florestas plantadas, eucalipto, volume de madeira, geoprocessamento.

\section{ESTIMATE OF THE AREA OCCUPIED BY REFORESTATION PROGRAMS IN RIO DE JANEIRO STATE}

\begin{abstract}
This study was based on a preliminary survey and inventory of existing reforestation programs in Rio de Janeiro state, through geoprocessing techniques and collection of field data. The reforested area was found to occupy 18,426.96 ha, which amounts to $0.42 \%$ of the territory of the state. Much of reforestation programs consists of eucalyptus (98\%), followed by pine plantations (0.8\%), and the remainder is distributed among 10 other species. The Médio Paraíba region was found to contribute the most to the reforested area of the state (46.6\%). The estimated volume of eucalyptus timber was nearly two million cubic meters. This study helped crystallize the ongoing perception among those militating in the forestry sector of Rio de Janeiro state that the planted area and stock of reforestation timber is still incipient in the state.
\end{abstract}

Key words: Planted forests, eucalyptus, timber volume, geoproceesing.

\section{INTRODUÇÃO}

O setor florestal brasileiro apresenta números que fazem com que o país se destaque no cenário internacional, ocupando atualmente a sexta posição no ranking de produtores mundiais, com cerca de 5,5 milhões de hectares $(0,6 \%$ do território nacional) ocupados com florestas plantadas (ASSOCIAÇÃO BRASILEIRA DE PRODUTORES DE FLORESTAS PLANTADAS ABRAF, 2006). A representatividade econômica do setor florestal brasileiro é destacada pela contribuição anual em torno de R\$ 26 bilhões (5\% do PIB nacional), mais de US\$ 4,1 bilhões (17\% das exportações do agronegócio e $8 \%$ do total das exportações) e arrecadação anual de $\mathrm{R} \$ 3$ bilhões em impostos (SOCIEDADE BRASILEIRA DE SILVICULTURA - SBS, 2005). Ressalta-se que, em comparação com outras modalidades de uso da terra, o reflorestamento ou plantio comercial de espécies arbóreas é a atividade agrícola que mais se recomenda para a conservação do solo, proteção dos mananciais e a recuperação de áreas degradadas (OLIVEIRA, 1997).

No que diz respeito aos aspectos sociais, o setor florestal é capaz de absorver mão de obra numerosa, colaborando, assim, para a melhor distribuição de renda para a população (CARVALHO et al., 2005). Porém, apesar de todo avanço desse setor, a produção de florestas

\footnotetext{
${ }^{1}$ Engenheiro Florestal, Professor Dr. - Departamento de Silvicultura - Instituto de Florestas - Universidade Federal Rural do Rio de Janeiro/UFRRJ BR 465, km 7 - 23890-000 - Seropédica, RJ - hamorim@ufrrj.br

${ }^{2}$ Agrônomo, Professor Dr. em Agronomia - Departamento de Silvicultura - Instituto de Florestas - Universidade Federal Rural do Rio de Janeiro/UFRRJ BR 465, km 7 - 23890-000 - Seropédica, RJ - marciorocha@ufrrj.br

${ }^{3}$ Bióloga, Professora Doutoranda em Ciências Ambientais e Florestais - Instituto Federal de Educação, Ciência e Tecnologia de São Paulo/IFSP Av. Rio Grande do Norte, 450, Indaiá - 11662-000 - Caraguatatuba, SP - salamene@yahoo.com.br

${ }^{4}$ Engenheiro Florestal - Departamento de Silvicultura - Instituto de Florestas - Universidade Federal Rural do Rio de Janeiro/UFRRJ - BR 465, km 7 23890-000 - Seropédica, RJ - lolprj@gmail.com, luizirenofilho@hotmail.com, rccapitano@yahoo.com.br

${ }^{5}$ Discente de Engenharia Florestal - Universidade Federal Rural do Rio de Janeiro/UFRRJ - BR 465, km 7 - $23890-000$ - Seropédica, RJ tom_adnet@yahoo.com.br
}

Cerne, Lavras, v. 18, n. 1, p. 27-32, jan./mar. 2012 
plantadas não atende à demanda anual de madeira no Brasil, em consequência, as florestas naturais acabam sofrendo os impactos dessa necessidade (EMPRESA BRASILEIRA DE PESQUISA AGROPECUÁRIA EMBRAPA, 2004). Essa é a situação do Estado do Rio de Janeiro que, atualmente, é grande importador dessa matéria-prima para diversos setores da sua economia (MOTTA, 2004) e sofre várias restrições de ordem legal para a expansão da atividade silvicultural em seu território.

Face à inexistência de dados oficiais confiáveis sobre o estoque de madeira de reflorestamento existente no Estado, neste trabalho, objetivou-se realizar levantamento da área destinada à produção florestal do Estado do Rio de Janeiro, utilizando técnicas de geoprocessamento, conjuntamente com trabalho de campo, além de identificar as espécies plantadas e estimar o volume de madeira disponível.

\section{MATERIAL E MÉTODOS}

\subsection{Cadastro e levantamento preliminar dos povoamentos} existentes

Essa fase foi composta pela consulta a documentos, empresas e profissionais da área florestal envolvidos com o plantio de florestas, no Estado do Rio de Janeiro, além de entidades governamentais, não-governamentais e busca na internet, com a finalidade de se organizar um cadastro básico dos povoamentos existentes. A ausência de qualquer cadastro dos reflorestamentos existentes no Estado do Rio de Janeiro transformou-se na principal dificuldade dessa etapa.

Foi realizado mapeamento prévio, utilizando diversas imagens do sensor HRC (High Resolution Camera) do satélite CBERS 2B, disponíveis gratuitamente no site do INPE (www.inpe.br). As mesmas foram reamostradas a partir das cartas do IBGE e processadas no programa ENVI 4.5. A vetorização foi realizada em tela, por meio da interpretação visual, utilizando o programa ArcGis 9.3, com auxílio de pontos de controles coletados nas áreas com plantio de eucalipto, utilizando equipamento de recepção de sinais de satélites do tipo navegação, modelo Garmin 76csx, de forma a determinar o padrão de resposta espectral na imagem HRC dos diferentes estágios fenológico da planta. Todas as imagens foram submetidas a filtros FTT Adiante para realçar os contrastes utilizando ferramentas do programa ENVI 4.5. Como as imagens HRC não cobriam toda a área de estudo, foi necessária a complementação com imagens disponíveis no Google Earth, composta principalmente por imagens do sensor Quick Bird, compreendendo o período de 2008 a 2009.
A área mínima identificável foi de 4 ha, porém plantios menores foram identificados no campo por meio de entrevistas e observações in situ.

\subsection{Planejamento e execução das campanhas de campo}

A partir da base de dados previamente construída, foram planejadas e executadas campanhas de campo durante três meses para a confirmação dos dados do mapeamento preliminar e obtenção de informações (espécies, idade, etc.) in situ, sobre povoamentos existentes nas regiões visitadas. Para tanto, foram contatados, durante essas campanhas, profissionais que atuam no setor, proprietários rurais, empresas de reflorestamentos e órgãos de extensão em vários municípios do Estado. Foram elaborados roteiros para visita aos reflorestamentos mapeados, procurandose maximizar o número de propriedades por roteiro, em função da malha viária existente. Foi utilizado sistema de navegação em tempo real disponível do programa Track Maker, a partir da base cartográfica elaborada e das imagens disponíveis, fazendo uso de receptor GPS tipo navegação conectado ao notebook.

A execução das campanhas de campo foi composta por três atividades principais:

- contato com pessoas e instituições envolvidas com os reflorestamentos, visando a identificar e ampliar o cadastro de informações;

- visita e documentação fotográfica dos povoamentos cadastrados;

- verificação e atualização do mapeamento preliminar, sendo que os povoamentos não identificados anteriormente foram registrados por meio do levantamento de suas coordenadas geográficas, sendo posteriormente vetorizados, utilizando o programa Arcgis 9.3 e incorporados a base de dados.

\subsection{Processamento dos dados}

As informações coletadas durante as campanhas de campo foram utilizadas para a revisão e a atualização do mapeamento preliminar e a agregação dos dados, segundo a região de ocorrência e espécie plantada, obtendo-se então o mapeamento definitivo. A partir dessas informações, efetuou-se uma estimativa preliminar do estoque existente.

Para a estimativa do volume atual desses povoamentos utilizou-se, como principal referencial, as observações coletadas sobre os mesmos durante as campanhas de campo (idade do plantio, área e espaçamento utilizado), informações bibliográficas disponíveis e dados fornecidos por empresas florestais.

Cerne, Lavras, v. 18, n. 1, p. 27-32, jan./mar. 2012 
Para fins de agregação e apresentação dos resultados, optou-se por dividir a área do Estado em oito regiões, conforme a Fundação CIDE (2009): Baixadas Litorâneas; Centro-Sul Fluminense; Costa Verde; Médio Paraíba; Metropolitana; Noroeste Fluminense; Norte Fluminense; Serrana.

\section{RESULTADOS E DISCUSSÃO}

O mapeamento definitivo identificou 1.077 polígonos associados a reflorestamentos no Estado do Rio de Janeiro, compreendendo uma área de 18.426,96 ha que corresponde a $0,42 \%$ do território fluminense (Figura 1). Desse total, 934 polígonos foram visitados (87\%).

A Região do Médio Paraíba respondeu por 46,6\% da área plantada, seguida pela Região Serrana, com 21,7\%, totalizando, ambas, $68,3 \%$ de todos os reflorestamento do estado (Tabela 1).

A região do Médio Paraíba, apesar de concentrar uma área maior, possui um número menor de áreas mapeadas que a Região Serrana. Explica-se esse fato em decorrência de duas circunstâncias:
- os reflorestamentos da Região Serrana localizamse, na sua maior parte, em pequenos e médios proprietários em condição de relevo bastante movimentado, dificultando a implantação de áreas com grande extensão;

- as principais empresas de reflorestamento do Estado do Rio de Janeiro encontram-se instaladas na Região do Médio Paraíba, em áreas de relevo plano a suave ondulado e em propriedades de razoável extensão, além do fato da proximidade com empresas de celulose localizadas na parte paulista do Vale do Paraíba.

As três regiões subsequentes em importância (Baixadas Litorâneas, Centro Sul Fluminense e Metropolitana) possuem a característica de concentrarem a maior parte de seus reflorestamentos em áreas menores, distribuídas em dois ou três fragmentos.

As regiões Norte e Noroeste Fluminense, nos últimos anos, vêm sendo procuradas por uma importante empresa florestal brasileira que empreende nas mesmas um programa de fomento florestal, resultando, no momento atual, em vários povoamentos em fase inicial de crescimento. A região da Costa Verde simplesmente continua com seu processo de exaustão dos povoamentos ali implantados, a maioria com idades superiores a 15 anos.

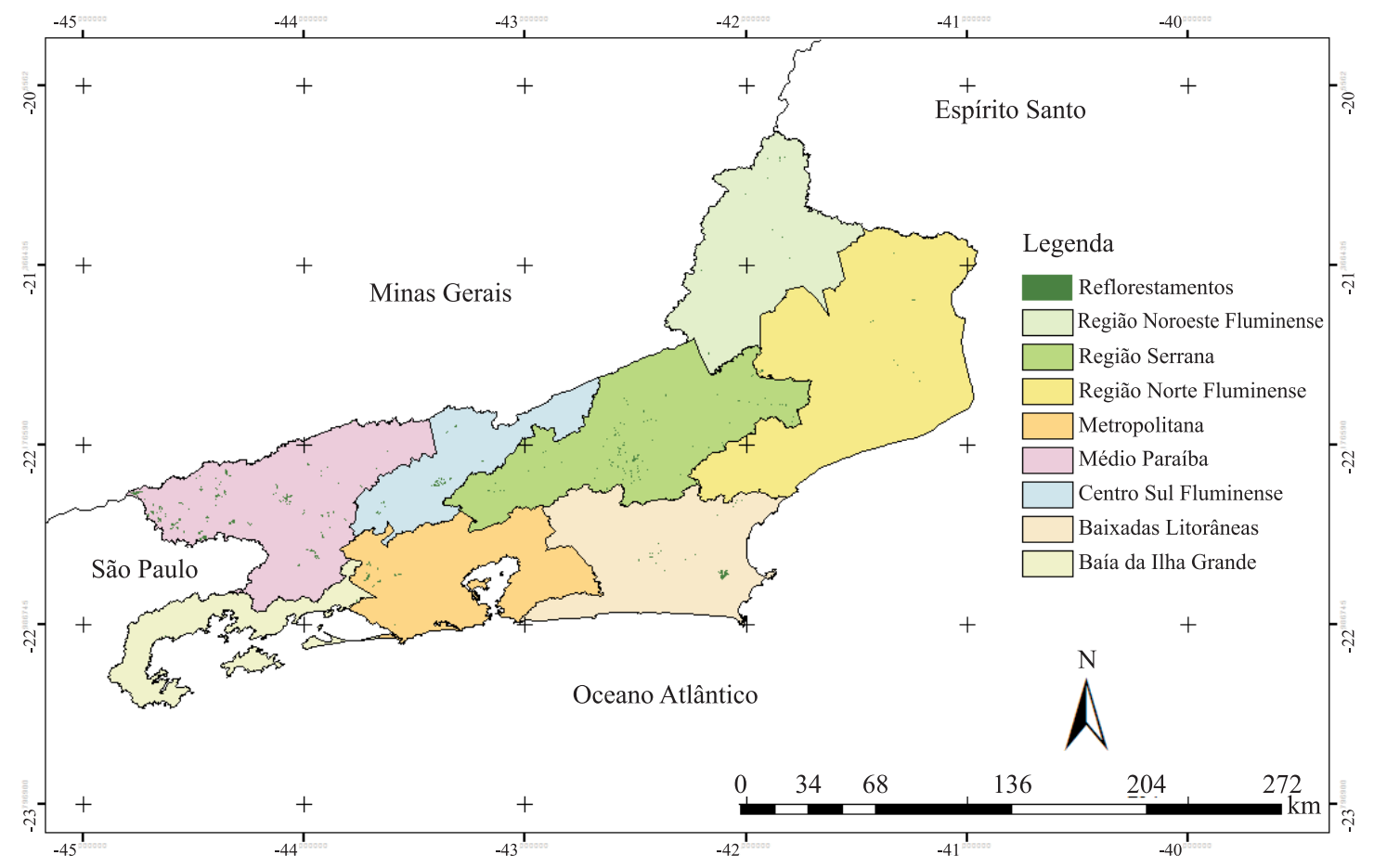

Figura 1 - Reflorestamentos identificados nas regiões do Estado do Rio de Janeiro.

Figure 1 - Reforestation sites identified in Rio de Janeiro state.

Cerne, Lavras, v. 18, n. 1, p. 27-32, jan./mar. 2012 
Tabela 1 - Área reflorestada por região do estado do Rio de Janeiro.

Table 1 - Reforested area per region of Rio de Janeiro state.

\begin{tabular}{lcc}
\hline \multirow{2}{*}{ Região } & \multicolumn{2}{c}{ Área } \\
\cline { 2 - 3 } & (ha) & (\%) \\
\hline Médio Paraíba & $8.587,26$ & 46,6 \\
Serrana & $4.003,67$ & 21,7 \\
Baixadas Litorâneas & $1.745,49$ & 9,5 \\
Centro-Sul Fluminense & $1.566,92$ & 8,5 \\
Metropolitana & $1.199,10$ & 6,5 \\
Norte Fluminense & 593,35 & 3,2 \\
Noroeste Fluminense & 525,32 & 2,9 \\
Costa Verde & 205,84 & 1,1 \\
\hline Total & $18.426,96$ & 100 \\
\hline
\end{tabular}

Mendonça-Santos et al. (2003) publicaram o mapeamento do uso e cobertura vegetal dos solos do Estado do Rio de Janeiro, onde verificou-se que as áreas de reflorestamento ocupavam, aproximadamente, 38,33 $\mathrm{km}^{2}$ (3.833 ha), representando 0,09\% da área total do Estado, valor bem distante do encontrado no presente estudo, cuja soma foi igual a mais de 18 mil hectares. Nessa publicação, os autores reconhecem que a área total reflorestada foi certamente subestimada nesse mapeamento, em razão da sua semelhança com a classe Mata Atlântica. Assim, diversas áreas de reflorestamento de pequena dimensão que não foram perfeitamente individualizadas, provavelmente foram englobadas no uso "Mata remanescente".

Nas áreas mapeadas, além de eucalipto e pinus, foram identificadas outras 10 espécies cultivadas (Tabela 2), com predominância do eucalipto, presente em 97,9\% das áreas, representando mais de 18 mil hectares de área plantada. As demais espécies têm participação insignificante, em termos de área plantada $(<1 \%)$. Em função desses resultados, apenas os reflorestamentos com eucalipto tiveram seus volumes estimados (Tabela 3).

Segundo Mendonça-Filho (1984), no final de 1977, o eucalipto correspondia a $89 \%$ do total de 10.598 ha de povoamentos plantados no Estado do Rio de Janeiro. A Microrregião que englobava os municípios de Barra do Piraí, Barra Mansa, Resende, Rio das Flores, Valença e Volta Redonda abrigava $75 \%$ da área plantada com eucalipto e $62 \%$ da área plantada com pinus. O resultado final do trabalho mostrou que na época o Estado do Rio de Janeiro possuía um estoque de madeira reflorestada de 1.478.891 $\mathrm{m}^{3}$ (volume total com casca), sendo 1.316.213 $\mathrm{m}^{3}$ desse total somente de eucalipto - pouco menos (aproximadamente $500 \mathrm{mil}$ ) do encontrado atualmente, após mais de três décadas.

Tabela 2 - Espécies identificadas nas áreas reflorestadas do Estado do Rio de Janeiro.

Table 2 - Species identified in reforested areas of Rio de Janeiro state.

\begin{tabular}{|c|c|c|c|c|c|}
\hline \multicolumn{2}{|r|}{ Espécie } & \multirow{2}{*}{ Família } & \multirow{2}{*}{$\begin{array}{l}\text { Número de } \\
\text { polígonos }\end{array}$} & \multicolumn{2}{|c|}{ Área } \\
\hline Nome vulgar & Nome científico & & & (ha) & $(\%)$ \\
\hline Eucalipto & Eucalyptus sp & Myrtaceae & 998 & $18.040,14$ & 97,91 \\
\hline Pinus & Pinus sp & Pinaceae & 37 & 156,73 & 0,845 \\
\hline Cedro australiano & Toona ciliata $\mathrm{M}$. Roemer var. australis & Meliaceae & 11 & 113,24 & 0,615 \\
\hline Seringueira & Hevea sp & Euphorbiaceae & 15 & 63,64 & 0,345 \\
\hline Palmeira real & $\begin{array}{c}\text { Archontophoenix alexandrae (F. Muell.) } \\
\text { H. Wendl. \& Drude. }\end{array}$ & Arecaceae & 6 & 22,31 & 0,121 \\
\hline Cedrinho & Cupressus lusitanica Mill. & Cupressaceae & 2 & 14,84 & 0,081 \\
\hline Pupunha & Bactris gasipaes Kunth & Arecaceae & 3 & 8,65 & 0,047 \\
\hline Teca & Tectona grandis L.F. & Verbenaceae & 1 & 3,82 & 0,021 \\
\hline Guapuruvu & Schizolobium parahyba (Vell.) Blake. & Leguminosae - Caesalpinoideae & 1 & 2,13 & 0,012 \\
\hline Sabiá & Mimosa caesalpiniaefolia Benth & Leguminosae - Mimosoideae & 1 & 0,77 & 0,004 \\
\hline Neem & Azadirachta indica A Juss. & Meliaceae & 1 & 0,41 & 0,002 \\
\hline Aroeira & Schinus terebinthifolius Raddi & Anarcadiaceae & 1 & 0,28 & 0,002 \\
\hline Total & 12 espécies & 10 famílias & 1077 & $18.426,96$ & 100 \\
\hline
\end{tabular}

Cerne, Lavras, v. 18, n. 1, p. 27-32, jan./mar. 2012 
Tabela 3 - Área e volume dos reflorestamentos com eucalipto por região do estado do Rio de Janeiro.

Table 3-Area and volume of eucalyptus reforestation per region of Rio de Janeiro state.

\begin{tabular}{lcccc}
\hline \multirow{2}{*}{ Região } & \multicolumn{2}{c}{ Área } & \multicolumn{2}{c}{ Volume } \\
\cline { 2 - 5 } & $(\mathrm{ha})$ & $(\%)$ & $\left(\mathrm{m}^{3}\right)$ & $(\%)$ \\
\hline Médio Paraíba & 8.431 & 46,7 & 793.192 & 41,9 \\
Serrana & 3.868 & 21,4 & 498.116 & 26,3 \\
Baixadas Litorâneas & 1.730 & 9,6 & 307.993 & 16,3 \\
Centro-Sul Fluminense & 1.567 & 8,7 & 98.611 & 5,2 \\
Metropolitana & 1.199 & 6,6 & 83.839 & 4,4 \\
Norte Fluminense & 562 & 3,1 & 43.595 & 2,3 \\
Noroeste Fluminense & 509 & 2,8 & 47.876 & 2,5 \\
Costa Verde & 173 & 1,0 & 21.273 & 1,1 \\
\hline Total & 18.040 & 100 & 1.894 .496 & 100 \\
\hline
\end{tabular}

O Instituto Brasileiro de Geografia e Estatística (IBGE) realiza, periodicamente, o Censo Agropecuário, onde coleta informações sobre a cobertura florestal dos estados, dividindo-a em matas naturais e matas plantadas. No período compreendido entre os anos de 1970 e 1985 , essa coleta de dados era realizada a cada cinco anos, sendo esse intervalo, a partir de então, modificado para cada 10 anos. Comparando-se os valores do Instituto Brasileiro de Geografia e Estatística - IBGE (2006), referentes aos anos de 1975 (34.213 ha) e 1980 (32.160), com aqueles apresentados pelo Inventário Florestal Nacional de florestas plantadas no Estado do Rio de Janeiro (MENDONÇA-FILHO, 1984) para o ano de 1977 (10.598 ha) verifica-se que existe diferenças entre os mesmos.

Mesmo levando-se em consideração as metodologias distintas e que os valores do Inventário Nacional referemse apenas aos povoamentos implantados por meio dos incentivos fiscais, a diferença em relação aos dados do IBGE, não pode ser creditada apenas aos povoamentos cuja implantação não guardava nenhuma vinculação com os incentivos fiscais. Dessa forma, pode-se especular que os resultados apresentados pelo IBGE para o período 19751985 encontram-se superestimados, tendo em vista que o Estado, nesse período, não foi contemplado com nenhum empreendimento de grande porte na área florestal.

Conforme mostrou a Tabela 2, outras espécies foram identificadas, principalmente pelas campanhas de campo, em virtude das reduzidas dimensões da maioria dos plantios, que não permitiu o mapeamento preliminar dos mesmos. No conjunto, essa ocorrência foi de apenas 2,1\% da área total mapeada. Pinus, seringueira e cedro australiano foram as ocorrências mais significativas, distribuindo-se por 16 municípios diferentes (Tabela 4). Merece destaque a implantação de povoamentos com cedro australiano, notadamente aqueles localizados no município de Resende.

Tabela 4 - Área (ha) ocupada pelos reflorestamentos com outras espécies em municípios do estado do Rio de Janeiro.

Table 4-Area (ha) occupied by reforestation with other species in municipalities of Rio de Janeiro state.

\begin{tabular}{|c|c|c|c|}
\hline \multirow{2}{*}{ Espécie } & \multirow{2}{*}{ Município } & \multicolumn{2}{|c|}{ Área do plantio } \\
\hline & & (ha) & $(\%)$ \\
\hline \multirow{9}{*}{ Pinus } & Teresópolis & 34,43 & 8,90 \\
\hline & Petrópolis & 29,78 & 7,70 \\
\hline & Angra dos Reis & 28,72 & 7,43 \\
\hline & Nova Friburgo & 20,36 & 5,26 \\
\hline & Barra do Piraí & 12,89 & 3,33 \\
\hline & Resende & 10,63 & 2,75 \\
\hline & Itatiaia & 8,01 & 2,07 \\
\hline & Valença & 7,99 & 2,07 \\
\hline & Mangaratiba & 3,90 & 1,01 \\
\hline \multirow{5}{*}{ Seringueira } & Campos dos Goytacazes & 31,68 & 8,19 \\
\hline & Silva Jardim & 14,82 & 3,83 \\
\hline & São Sebastião do Alto & 7,03 & 1,82 \\
\hline & Itaperuna & 5,84 & 1,51 \\
\hline & Natividade & 4,26 & 1,10 \\
\hline \multirow{4}{*}{ Cedro australiano } & Resende & 84,98 & 21,97 \\
\hline & Santa Maria Madalena & 16,05 & 4,15 \\
\hline & Trajano de Morais & 12,01 & 3,11 \\
\hline & Miracema & 0,20 & 0,05 \\
\hline \multirow{2}{*}{ Palmeira real } & Pinheiral & 20,16 & 5,21 \\
\hline & Rio Claro & 2,15 & 0,56 \\
\hline \multirow{3}{*}{ Pupunha } & Valença & 7,21 & 1,86 \\
\hline & Natividade & 0,96 & 0,25 \\
\hline & Miracema & 0,48 & 0,12 \\
\hline Cedrinho & Nova Friburgo & 14,84 & 3,84 \\
\hline Теса & Miracema & 3,82 & 0,99 \\
\hline Guapuruvu & Barra Mansa & 2,13 & 0,55 \\
\hline Sabiá & Santa Maria Madalena & 0,77 & 0,20 \\
\hline Neem & Itaocara & 0,41 & 0,11 \\
\hline Aroeira & São Pedro da Aldeia & 0,28 & 0,07 \\
\hline Total & - & 386,79 & 100 \\
\hline
\end{tabular}

Cerne, Lavras, v. 18, n. 1, p. 27-32, jan./mar. 2012 
Segundo Mendonça-Filho (1984), no início da década de 80, o Estado do Rio de Janeiro detinha 1.147,44 ha de Pinus sp implantados, correspondendo a $10,83 \%$ do total dos reflorestamentos existentes no estado. As principais espécies plantadas foram Pinus caribaeae Morelet e Pinus elliottii Engelm, distribuídas majoritariamente pelo Vale do Paraíba e, em menor escala, pela região da Costa Verde. No presente trabalho, foram mapeados 156,71 ha de pinus, distribuídos por 9 municípios (Tabela 4).

\section{CONCLUSÕES}

Por meio dos resultados obtidos, pode-se concluir que:

- a área total dos reflorestamentos (18.426,96 ha) correspondeu a $0,42 \%$ da área do estado, com maior concentração na região do Médio Paraíba;

- foram encontradas 12 espécies florestais plantadas, sendo a grande maioria das áreas ocupadas por eucalipto (98\%);

- o volume atual de madeira estimado para o eucalipto foi de quase dois milhões de metros cúbicos;

- o uso de imagens HRC com apoio de visita ao campo mostrou-se eficiente para o estudo de povoamento florestal homogêneo.

\section{AGRADECIMENTOS}

Agradecemos à Federação das Indústrias do Estado do Rio de Janeiro (FIRJAN), pelo apoio financeiro.

\section{REFERÊNCIAS}

ASSOCIAÇÃO BRASILEIRA DE PRODUTORES DE FLORESTAS PLANTADAS. Anuário estatístico: ano base 2006. Brasília, 2007. 80 p.

Cerne, Lavras, v. 18, n. 1, p. 27-32, jan./mar. 2012
CARVALHO, R. M. M. A. et al. Caracterização do setor florestal: uma abordagem comparativa com outros setores da economia. Ciência Florestal, Santa Maria, v. 15, n. 1, p. 105118, 2005.

EMPRESA BRASILEIRA DE PESQUISA

AGROPECUÁRIA. Florestas: a Embrapa conserva este patrimônio. Brasília, 2004.

FUNDAÇÃO CIDE. Rio de Janeiro em dados 2008.

Disponível em: <http://www.cide.rj.gov.br/cide/download/ Rio_em_Dados_2008.pdf>. Acesso em: 22 nov. 2009.

INSTITUTO BRASILEIRO DE GEOGRAFIA E

ESTATÍSTICA. Censo agropecuário 2006. Rio de Janeiro, 2006. $146 \mathrm{p}$.

MENDONÇA-FILHO, W. F. (Coord.). Inventário florestal nacional: reflorestamento: Rio de Janeiro e Espírito Santo. Brasília: IBDF, 1984.

MENDONÇA-SANTOS, M. L. et al. Mapeamento do uso atual e cobertura vegetal dos solos do Estado do Rio de Janeiro. Rio de Janeiro: Embrapa Solos, 2003. 44 p.

MOTTA, F. G. Relatório setorial preliminar. Rio de Janeiro: FINEP, 2004.

OLIVEIRA, J. T. S. Caracterização da madeira de eucalipto para a construção civil. 1997. 450 f. Tese (Doutorado em Engenharia) -Universidade de São Paulo, São Paulo, 1997.

SOCIEDADE BRASILEIRA DE SILVICULTURA. Fatos e números do Brasil Florestal 2005. São Paulo, 2005. 105 p. 